\title{
PARTIAL TRISOMY FOR 7p DUE TO MATERNAL BALANCED TRANSLOCATION
}

\author{
Shozo OHdo, ${ }^{1}$ Kaoru Suzumori, ${ }^{2}$ Harumichi MAdokoro, ${ }^{1}$ \\ Tohru Sonoda, ${ }^{1}$ and Kunio HayaKawa ${ }^{1}$ \\ ${ }^{1}$ Department of Pediatrics, Miyazaki Medical College, 5200 Kihara, Kiyotake-cho, \\ Miyazaki 889-16, Japan \\ ${ }^{2}$ Department of Obstetrics and Gynecology, Faculty of Medicine, Nagoya City \\ University, 1 Kawasumi, Mizuho-ku, Nagoya 467, Japan
}

Summary A patient with the karyotype of $46, \mathrm{XY}$, der(11), (7;11) (p15; q25)mat is reported. The major clinical findings of the present case included psychomotor retardation, growth retardation after birth, wide anterior fontanel, left esotropia, sacral dimple, bilateral undescended testis, whorls on six fingers, unilateral palmar transverse crease, and bilateral high axial triradius.

Prenatal diagnosis was carried out on the fetus conceived subsequent to the birth of the proband. The karyotype of the fetus proved to be $46, \mathrm{XX}$, der(11), $\mathrm{t}(7 ; 11)(\mathrm{pl} ; \mathrm{q} 25)$ mat, so that induced abortion was performed. Only micrognathia was a conspicuous finding in the fetus.

\section{INTRODUCTION}

Among the seven cases with trisomy for $7 \mathrm{p}$ reported previously, clinical findings were described in six cases, in addition dermatoglyphic findings were described in two cases. We examined consistent findings of the clinical features of these cases and the present case.

\section{CASE REPORTS}

Case 1.

The proband was delivered on December 24,1981 , to a 25 years old primigravida woman after normal pregnancy, by cesarean section due to her contracted pelvis. His parents were healthy and unrelated, the father being 30 years old. He was $3,230 \mathrm{~g}$ in weight, $49.2 \mathrm{~cm}$ in height and $33.6 \mathrm{~cm}$ in head circumference when delivered. No asphyxia was noted. 
On June 23, 1982, he was referred to our outpatient-clinic for feeding difficulty and retardation in somatic development. On physical examination at five months after birth (Fig. 1), height was $60.0 \mathrm{~cm}$ (-2.8 SD), weight was $5,530 \mathrm{~g}(-3.1 \mathrm{SD})$ and head circumference was $42.1 \mathrm{~cm}(-1.0 \mathrm{SD})$. The anterior fontanel was widely open $(6 \times 6 \mathrm{~cm})$, and the metopic suture and the sagittal suture were separated. Left esotropia, sacral dimple and bilateral undescended testis were observed. Although high-arched palate was noted, it corresponded to his age. No abnormalities of auricles were found. Heart murmur was not heard.

Dermatoglyphic study showed finger patterns consisting of six whorls and four ulnar loops both on the first and second fingers. On the palms, right palmar transverse crease and bilateral high axial triradius ( $65^{\circ}$ on both palms) were observed.

Routine blood investigations, including serum electrolyte, protein and immunoglobulin level, and urinalysis were all normal.

Chest X-ray, ECG and EEG findings were within normal limits. The CT scan of the brain revealed mild dilatation of lateral ventricles.

Leukocyte cultures from the peripheral blood showed an extra band on the terminal region of the long arm of chromosome 11 . While the karyotype of the father was normal, that of the mother was $46, X X, \operatorname{rcp}(7 ; 11)(\mathrm{p} 15 ; \mathrm{q} 25)$. Accordingly,

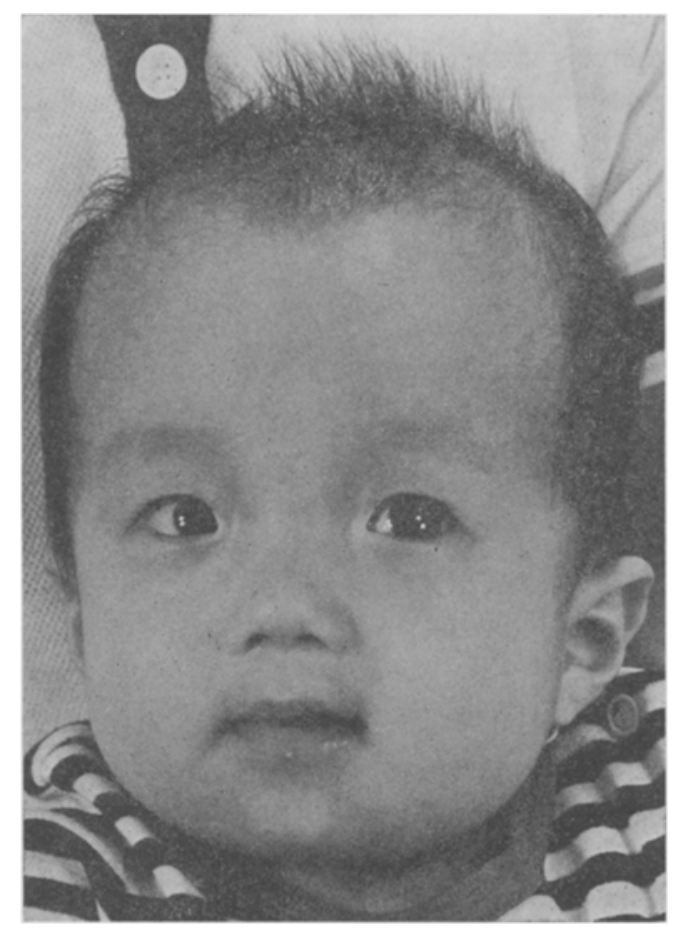

Fig. 1. Facial appearance of proband at the time of eight months after birth. His facial appearance was indistinctive, except for esotropia.

Jpn. J. Human Genet. 


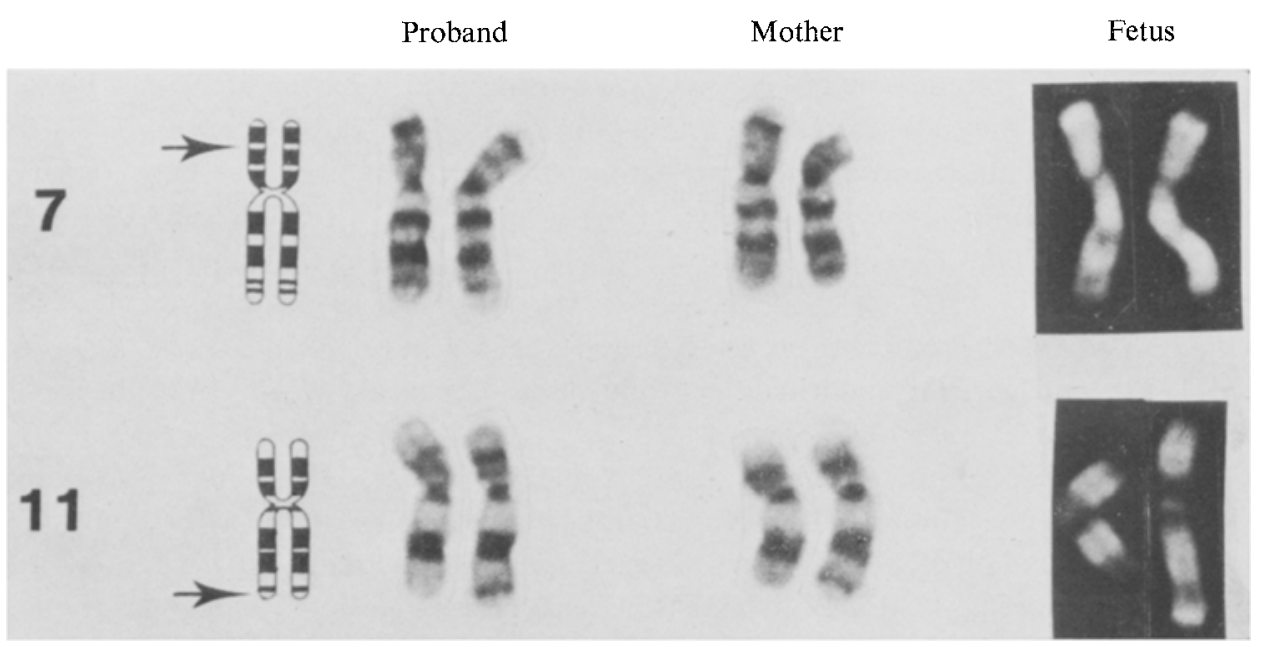

Fig. 2. Partial karyotype of proband (G-band), his mother (G-band) and subsequent fetus (Q-band).

the karyotype of the patient proved to be $46, \mathrm{XY}$,der(11), t(7;11)(p15;q25)mat (Fig. 2).

At the time of 13 months after birth, his height was $69.0 \mathrm{~cm}(-2.8 \mathrm{SD})$, weight was $8,400 \mathrm{~g}(-1.4 \mathrm{SD})$ and head circumference was $46.2 \mathrm{~cm}$ (nearly the standard level). The size of the anterior fontanel was $5 \times 5 \mathrm{~cm}$, and the developmental quotient was about 45 .

Case 2.

When the mother of the proband subsequently conceived, prenatal diagnosis of the fetus was carried out in January 1983. The result indicated the karyotype of $46, X X$, der(11), $t(7 ; 11)$ (p15;q25) (Fig. 2). Upon the request of the parents, induced abortion was performed. No marked abnormalities, except for micrognathia, were found in the fetus.

\section{DISCUSSION}

Seven cases with trisomy for $7 \mathrm{p}$, partial or complete, were confirmed by chromosome analysis (Larson, 1977; Carnevale et al., 1978; Berry et al., 1979; Miller et al., 1979; Moore et al., 1982). The case dealt with in this paper is the eighth to be reported.

Chromosomal aberrations found in all these eight patients resulted from balanced translocations in their fathers (Larson, 1977; Berry et al., 1979; Moore et al., 1982), or in their mothers (Carnevale et al., 1978; Miller et al., 1979; Moore et al., 1982 and present case). Segments of duplication are mostly found from $7 \mathrm{p} 15$ to 7pter. This was true in four cases, including one case in this paper (Berry et al., 1979; Moore et al., 1982). 
We analyzed the clinical findings of the seven cases. Since the clinical findings of Miller's case were not described, we have not included it in our analysis. It was found that the only clinical features common to all seven cases were severe developmental retardation and growth retardation after birth. Other consistent findings were cardiovascular abnormalities (five of the seven. Larson, 1977; Carnevale et al., 1978; Berry et al., 1979; Moore et al., 1982), wide anterior fontanel (five cases. Carnevale et al., 1978; Berry et al., 1979; Moore et al., 1982 and present case), dolichocephaly or prominent occiput (three cases. Carnevale et al., 1978; Berry et al., 1979), and skeletal abnormalities (four cases. Carnevale et al., 1978; Berry et al., 1979; Moore et al., 1982).

Detailed description on dermatoglyphic findings was made only by Moore et al. (1982) and by the authors. In one case reported by Berry et al. (1979), only the existence of unilateral palmar transverse crease was described. In two cases reported by Moore et al. (1982), palmar transverse creases on both palms were found. Unilateral palmar transverse crease were observed in one case reported by Berry et al. (1979) and in the present case. In Moore's two cases and in our case an increase of whorls was noted. In one case reported by Moore et al. (1982) and in our case, bilateral high axial triradius were detected.

Birth weight ranged from 2,300 g (Berry et al., 1979) to 4,650 g (Carnevale et $a l ., 1978$ ), so that birth weight was not always low. As to the life expectancy, there have been only two reports of death (at eight months after birth by Berry et al., and at seven months by Carnevale et al.). However, since the number of reported cases is so small, no definite evaluation is possible as yet.

As mentioned above, clinical findings varied according to the cases, which might be attributable to the cytogenetic heterogeneity of patients. In the cases of Berry et al. (1979), however, although the conditions of the chromosomes were equal, the clinical features and life expectancy varied.

The authors could not find pathognomonic signs in cases with trisomy for $7 \mathrm{p}$. It might be possible, however, that a combination of clinical findings such as growth retardation after birth, developmental retardation, wide anterior fontanel observed at infancy, cardiovascular abnormalities, dermatoglyphic findings including the increase of whorls and high axial triradius and palmar transverse creases, might suggest trisomy for $7 \mathrm{p}$.

\section{REFERENCES}

Berry, A.C., Honeycombe, J., and Macoun, S.J.R. 1979. Two children with partial trisomy for 7p. J. Med. Genet. 16: 320-321.

Carnevale, A., Frias, S., and der Castillo, V. 1978. Partial trisomy of the short arm of chromosome 7 due to a familial translocation $\operatorname{rcp}(7 ; 14)(\mathrm{p} 11 ; \mathrm{p} 11)$. Clin. Genet. 14: 202-206.

Larson, L.M., Wasdahl. W.A., and Jalal, S.M. 1977 . Partial trisomy $7 p$ associated with familial $7 \mathrm{p} ; 22 \mathrm{q}$ translocation. J. Med. Genet. 14: 258-261.

Miller, M., Kaufman, G., Reed, G., Bilenker, R., and Schinzel, A. 1979. Familial, balanced insertional translocation of chromosome 7 leading to offspring with deletion and duplication of the inserted segment, $7 \mathrm{p} 15 \rightarrow 7 \mathrm{p} 21$. Am. J. Med. Genet. 4: 323-332.

Moore, C.M., Pfeiffer, R.A., Craig-Holmes, A.P., Scott, C.I., Jr., and Meisel-Stosiek, M. 1982. Partial trisomy $7 \mathrm{p}$ in two families resulting from different balanced translocation. Clin. Genet. 21: $112-121$. 